\title{
A eficácia das transferências de renda: as tendências da desigualdade antes e depois do Programa Bolsa Família
}

\author{
Carlos Rosano Peña \\ Universidade de Brasília (UnB) / Departamento de Administração \\ Brasília / DF - Brasil \\ Danielle Sandi Pinheiro \\ Universidade de Brasília (UnB) / Departamento de Administração \\ Brasília / DF - Brasil \\ Pedro H. M. Albuquerque \\ Universidade de Brasília (UnB) / Departamento de Administração \\ Brasília / DF - Brasil \\ Loyane Mota Fernandes \\ Universidade de Brasília (UnB) / Departamento de Administração \\ Brasilia / DF - Brasil
}

\begin{abstract}
Ao propor a utilização dos métodos cadeia de Markov e diferenças em diferenças na análise da eficácia do Programa Bolsa Família este trabalho buscou contribuir para o estado da arte na temática de estudos aplicados das políticas públicas de transferência de renda. Fez-se uso combinado desses métodos em dois períodos: antes da implantação do Programa e após sua implantação. Os resultados revelaram que, após a implantação do Bolsa Família, o "ciclo da pobreza" apresentou sinais de ruptura, devido a uma tendência de convergência para níveis de renda mais elevados e probabilidade de mitigar a pobreza nas classes de renda menos favorecidas da população brasileira. Assim, no longo prazo, vislumbra-se a possibilidade de alterar e combater a dinâmica do ciclo da pobreza e exclusão social.
\end{abstract}

Palavras-chave: pobreza; concentração de renda; cadeia de Markov.

La efectividad de la transferencia de ingresos: las tendencias de la desigualdad antes y después del programa bolsa família

Al proponer el uso del método cadena de Markov y diferencias en diferencias en el análisis de la efectividad del programa Bolsa Família este estudio buscó contribuir al estado del arte en estudios aplicados

DOI: http://dx.doi.org/10.1590/0034-7612135532

Artigo recebido em 28 maio 2014 e aceito em 27 jan. 2015.

(cc) BY-NC

Rev. Adm. Pública - Rio de Janeiro 49(4):889-913, jul./ago. 2015 
de políticas públicas de transferencia de ingresos. Fue utilizado el uso combinado de estos métodos en dos períodos: antes de la implementación del programa y después de su implementación. Los resultados revelaron, después de la aplicación de Bolsa Família, que el "ciclo de la pobreza" presenta signos de ruptura, debido a una tendencia de convergencia hacia los niveles más altos de ingresos y una oportunidad para mitigar las clases empobrecidas de los ingresos de la población. Por lo tanto, a largo plazo, existe la posibilidad del cambio y combate la dinámica del ciclo de la pobreza y la exclusión social.

Palabras clave: pobreza; políticas públicas; concentración de la renta.

The effectiveness of income transfers: trends of inequality before and after Bolsa Família program In proposing the use of Markov Chain and differences in the analysis of the effectiveness of Bolsa Família program, this study sought to contribute to the state of the art in applied studies of public policies of income transfer. The combined use of these methods was used in two periods: before the implementation of the program and after it. The results revealed that, after the implementation of Bolsa Família, the "cycle of poverty" presented signs of rupture, due to a tendency of convergence to higher levels of income and because of the likelihood of mitigating the poorest income classes of the Brazilian population. Thus, on long-term, there is the possibility of changing and combating the dynamics of the cycle of poverty and social exclusion in Brazil.

KEYWORDs: poverty; income concentration; Markov chain.

\section{Introdução}

Na virada do século XX, políticas de transferência de renda condicionadas ganharam particular relevância na agenda nacional, quando nasceram os Programas de Erradicação do Trabalho Infantil, Bolsa Escola, Bolsa Alimentação, entre outros. Estas políticas sociais tinham dois objetivos centrais: o alívio da pobreza no curto prazo e o combate a sua transmissão intergeracional. Tendo como alvo a parcela mais empobrecida da população brasileira, esses benefícios exigiam contrapartidas consistentes, principalmente quanto à frequência escolar mínima de $85 \%$ no ano para crianças de 6 a 15 anos, aleitamento materno, exames pré-natais para gestantes e vacinação das crianças.

Em outubro de 2003 com a instituição do Ministério de Desenvolvimento Social e Combate à Fome (MDS), ocorreu a unificação desses programas, criando-se o Programa Bolsa Família (PBF). O PBF consiste basicamente na integração dos benefícios monetários concedidos às famílias em situação de pobreza, em função do número de crianças e adolescentes que as constituem. Buscou-se, assim, superar a fragmentação e o paralelismo dos programas anteriores, bem como a induzir uma sinergia nacional sob uma gestão única. A unificação de tais programas, segundo a lei que criou o PBF, visou a "melhorar a gestão e aumentar a efetividade do gasto social através da otimização, racionalização e ganhos de escala e facilidade de interlocução do Governo Federal com estados e municípios" (Brasil, 2004).

Convém ressaltar que o PBF enfatiza o cumprimento de condicionalidades (ou contrapartidas) por parte das famílias beneficiadas. Uma nova exigência do governo federal se refere 
à necessidade de renovação dos dados cadastrais dos beneficiados a cada dois anos, ocasião na qual a condição do beneficiário é reavaliada. Também é conveniente mencionar que são implementadas ações complementares de acompanhamento socioassistencial das famílias que não estão conseguindo cumprir as condicionalidades.

Dando origem a um novo desenho institucional das políticas de transferência de renda no Brasil, o PBF expandiu-se fortemente, tanto em termos de cobertura, quanto em valor do benefício. Segundo o Ministério do Planejamento, Orçamento e Gestão (MPOG), quando foi lançado, o programa recebeu R \$ 3,2 bilhões para atender a 3,6 milhões de famílias; em 2012, seu orçamento cresceu para R\$20,2 bilhões, beneficiando 13,7 milhões de lares.

Desde a sua criação o PBF tem gerado um crescente interesse no meio político, acadêmico e governamental. E, entre outros temas, vem exigindo dos pesquisadores respostas à seguinte questão: são os programas de transferência de renda eficazes na redução da desigualdade e da pobreza?

Inúmeros trabalhos teóricos e empíricos, nacionais e internacionais, têm tratado desse tema. Observa-se, entretanto, que não existe consenso. Enders e Hoover (2003), por exemplo, ressaltam que não são claros os impactos dos programas de transferência de renda na literatura internacional e mostram empiricamente que essas políticas nos EUA não têm efeito significativo sobre a pobreza. Resultados semelhantes foram encontrados por Marinho, Linhares e Campelo (2011) numa investigação da dinâmica recente da pobreza no Brasil, na qual foi constatado que não houve uma relação estatisticamente significante entre transferências de renda e pobreza no Brasil. De acordo com os autores, a política educacional tem maior peso na redução da desigualdade de renda.

Para Carvalho (2006), os críticos desses programas argumentam que essas transferências desmotivam os pobres a procurar emprego e buscar qualificação profissional, tornando-os dependentes do auxílio. Assim, segundo Rector e Lauder (1995), as famílias escolheriam continuar no limite da pobreza para receber os benefícios. Esse fenômeno é conhecido como "efeito preguiça".

Entretanto, os partidários dos programas de transferência de renda replicam que as bolsas no Brasil são extremamente baixas (de $\mathrm{R} \$ 32$ a $\mathrm{R} \$ 306$ ) e, por isso, não gerariam problemas de desincentivo ao trabalho. Segundo Medeiros Brito e Soares (2007), dados do Instituto Brasileiro de Geografia e Estatística (IBGE) mostram que pessoas que vivem em domicílios onde há beneficiários do Bolsa Família trabalham tanto ou mais do que as outras pessoas com renda familiar per capita similar. Além disso, esse impacto sobre a oferta de trabalho é maior entre as mulheres do que entre os homens, o que, para tais autores, abate as críticas de que as transferências perpetuam as desigualdades de gênero à medida que o benefício permitisse que as mulheres se retirassem do mercado de trabalho e se dedicassem ao cuidado das crianças, idosos e pessoas deficientes. A igual conclusão chega Tavares (2008) em uma pesquisa que constata o efeito positivo do Programa Bolsa Família sobre a oferta de trabalho das mães beneficiadas.

De outra perspectiva, Carvalho (2006) constata que existem aspectos positivos nesses instrumentos de redistribuição. Entretanto, para o pesquisador, como os recursos são 
escassos, os gastos crescentes com tais benefícios requerem um contingenciamento dos investimentos em outras áreas sociais: educação, geração autônoma de renda, infraestrutura etc., que podem desfazer no futuro o círculo de dependência do beneficiário e dinamizar as economias locais.

Nessa mesma linha, Caetano (2008) acrescenta que há um arcabouço eficaz para atenuar as desigualdades no curto prazo, mas que, em tese, isso se mostra ineficiente em alterar a essência do problema no longo prazo, ou seja, a pobreza continuará persistindo mesmo com o aumento da transferência. A situação ideal seria que o PBF fosse um mecanismo temporário.

No entanto, outros artigos empíricos mostram que esses programas estão cumprindo a função a que se destinam, têm bom desempenho em comparações internacionais, geram impacto relevante sobre a redução da pobreza e da desigualdade e apresentam custo compatível com a capacidade orçamentária brasileira. Dentre eles, podem-se citar as pesquisas de Rocha (2004, 2006), Kakwani, Neri e Son (2006) e Medeiros, Brito e Soares (2007).

Para testar a eficácia das ações de transferência de renda no combate à pobreza utilizam-se variadas modelagens. Como exemplo podem-se citar os métodos de avaliação de impacto e as técnicas não paramétricas de cadeias de Markov. Os métodos de avaliação de impacto permitem responder à seguinte questão: as melhorias observadas nos níveis de pobreza nos últimos anos teriam acontecido de qualquer forma, mesmo se o PBF não tivesse sido implantado? Baker (2000), Ravallion (2007), Tavares (2008), Soares e Sátyro (2010) e Gertler e colaboradores (2011) são exemplos deste tipo de abordagem.

As técnicas não paramétricas de cadeias de Markov estudam as tendências temporais da pobreza e a mobilidade da distribuição da renda, onde o quadro passado exibe mudanças que devem influenciar o quadro futuro. Tais modelos têm as vantagens de: a) estimar a perpetuidade ou não da pobreza e a concentração de renda, b) testar a hipótese de convergência ou divergência desses indicadores entre países e regiões, c) se há formação, ou não, de clubes fechados de convergência e d) prever qual o tempo necessário para as transformações na distribuição de renda. Dentre os trabalhos que utilizam esse método, podem-se citar as pesquisas de Rocha e Vergolino (2002), Azzoni (2009) e Menezes, Silveira Neto e Azzoni (2012).

Nota-se, entretanto, que a maioria dos trabalhos que estuda tendências com cadeias de Markov foi feita utilizando um único período. Não há referências à utilização desse método no estudo da dinâmica em dois períodos diferentes como antes e depois da implantação de um programa como forma de avaliação da eficácia de políticas públicas. Justamente, com vistas a preencher essa lacuna, o presente estudo se propõe. É nesse contexto que surge a principal motivação e objetivo do presente artigo: analisar a tendência e a mobilidade na distribuição da renda antes e depois do PBF, a fim de se testar a eficácia desse programa de transferência de renda, aplicando-se os métodos cadeia de Markov e diferenças em diferenças.

O uso concomitante desses dois métodos se justifica porque é de se esperar que se em um, ou em dois períodos comparativos (antes e depois da implantação do PBF), não se comprovar, na distribuição de renda, tendências de convergência em direção à redução da pobreza, pode ser rejeitada a hipótese de que essa política de transferência de renda é eficaz, já que ser eficaz consiste em conseguir atingir o objetivo dado. Por outro lado, se houver a compro- 
vação de uma tendência de convergência em direção à redução da pobreza e desigualdade de renda, não se pode aceitar absolutamente a hipótese de eficácia do PBF. A evidência de convergência não é suficiente para provar a eficácia desse programa. A convergência é condição necessária para a eficácia, mas não é suficiente, pois pode ser resultado de outros fatores. Isso significa apenas um indício. Contudo, se o resultado obtido pelo método cadeia de Markov for confrontado com outras evidências estimadas pelo método de avaliação de impacto do tipo diferenças em diferenças, poderá surgir a prova para aceitar ou rejeitar a hipótese de eficácia do Bolsa Família.

\section{Pobreza e desigualdade de renda}

Apesar de ser considerado um país emergente e possuir um enorme potencial de recursos naturais, o Brasil ainda depara-se com elevados níveis de pobreza e desigualdade na distribuição pessoal e regional da renda. Mesmo tendo passado nos últimos anos por modificações nas características distributivas, a renda apropriada em 2013 pelos 1\% mais ricos da população brasileira é 16,67 vezes maior do que a renda dos $40 \%$ mais pobres, conforme mostram dados compilados pela base de dados Ipeadata.

O problema da miséria, da concentração da renda e da desigualdade regional tornou-se mais evidente com a expansão da economia brasileira. Isso resultou não somente de uma única causa, mas de um conjunto de múltiplos fatores. Entre eles estão baixa instrução, serviços públicos insuficientes, corrupção, elevada carga tributária sem a contrapartida de prestação de serviços públicos de qualidade e desigualdades de oportunidades. Além disso, a relação causa-efeito amplifica-se como fruto da retroalimentação, onde cada elemento afetando e sendo afetado pelo outro reproduz o ciclo vicioso da pobreza.

Agravando esse problema, as tradicionais políticas econômicas do país durante muito tempo priorizaram o crescimento econômico. Acreditava-se que essa era a condição básica para o desenvolvimento inclusivo, consubstanciado por um processo social e uma convergência regional.

O questionamento desse paradigma tomou força nas últimas décadas e um crescente número de trabalhos nacionais e internacionais tem sido produzido, em decorrência da constatação empírica em diversos países de que a expansão econômica não necessariamente beneficia todos os indivíduos (e regiões) e pode ter efeitos essencialmente concentradores. Uma dessas evidências na história brasileira é mostrada no período do chamado "milagre econômico", onde houve um aumento da concentração de renda e da pobreza. Segundo Hoffman (2006), todas as medidas de desigualdade mostram crescimento nesse período, com alteração mais intensa entre 1960 e 1970.

Outra constatação é dada por Gafar (1998) na análise da América Latina. O autor conclui que o crescimento econômico é uma condição necessária para reduzir a pobreza, pois aumenta as oportunidades de emprego, o padrão de vida e os salários reais. Porém, não é uma condição suficiente; se o padrão de crescimento for meramente urbano, intensivo em capital e 
empregador predominantemente de mão de obra qualificada. Nesse caso, a pobreza pode até mesmo crescer com o aumento do produto interno bruto.

Nesse sentido, Kageyama e Hoffman (2006) acrescentam que o Brasil teria entrado num padrão de "círculo vicioso" na década de 1990, em que os baixos padrões de desenvolvimento humano passaram a restringir o crescimento econômico e foram sucessivamente limitados por este. Barros, Henriques e Mendonça (2001) ressaltam que a desigualdade na distribuição de renda é responsável pelo fato de o crescimento econômico ser relativamente menos eficiente do que poderia ser na redução da pobreza, ou seja, o efeito do crescimento sobre a redução da pobreza é menor no Brasil do que em outros países que alcançaram o mesmo nível de renda.

Resultados semelhantes foram encontrados para um conjunto de países de várias regiões por Bourguignon (2002) e na China e Índia por Ravallion (2005). Para Banerjee e Duflo (2003), quanto mais desigual um país ou região for, menor será a taxa de crescimento econômico, uma vez que se tem um desestímulo ao investimento pelos efeitos negativos da baixa renda e do reduzido consumo. Outros argumentos, como a instabilidade sociopolítica e alta restrição de crédito, presentes num contexto de elevada desigualdade de renda, reduzem o investimento na economia e, por consequência, a taxa de crescimento.

Portanto, para Barreto (2005), políticas que promovam a queda da desigualdade são mais relevantes do que políticas de expansão da renda no combate à pobreza. Assim, os problemas de desequilíbrio regional, como é o caso da região Nordeste, devem ser combatidos por meio de políticas de crescimento econômico, acompanhadas de uma melhor distribuição de renda.

Por outro lado, Soares e colaboradores (2007) mostram que a erradicação da miséria e a redução substancial da desigualdade são objetivos dificilmente alcançáveis dentro de um prazo razoável sem que se recorra a programas de transferência de renda. O trabalho de Barros e colaboradores (2007) complementa essa tese.

\subsection{Conceitos e medidas de pobreza e desigualdade}

Por ser a pobreza um fenômeno multidimensional, sua conceituação tem gerado muitas discussões. Para Townsend (1979), o conceito de pobreza tem três abordagens básicas: pobreza absoluta, pobreza relativa e pobreza de privação ou capacidade.

Considera-se que uma família ou indivíduo está numa situação de pobreza absoluta quando suas condições de vida estão abaixo do limite mínimo de sobrevivência, denominado linha de pobreza. Uma das primeiras medidas de linha de pobreza foi apresentada em 1963 por Mollie Orshansky (1965). Esse parâmetro é utilizado até os dias atuais como indicador para distinguir a população total em pobres e não pobres nos Estados Unidos.

Todavia, não existe um consenso na literatura quanto ao método de construção de linhas de pobreza. Alguns autores usam como referência os gastos para o consumo diário das calorias mínimas necessárias (aproximadamente 2.000/2.500 quilocalorias), definindo a linha de indigência ou pobreza extrema e acrescentando um conjunto de outras necessidades 
básicas (habitação, vestuário, higiene, saúde, educação, transporte, lazer etc.) para estimar a linha de pobreza moderada, conforme destaca Rocha (2006). Outros pesquisadores adotam o critério do salário mínimo ou um de seus múltiplos por sua simplicidade, conforme pode ser conferido em Laderchi e Stewart (2006). O Banco Mundial segue o critério de 1 dólar por dia para definir a pobreza extrema e para a pobreza moderada entre 1 e 2 dólares diários, convertidos pela paridade do poder de compra (World Bank, 2003).

De acordo com o MDS, o critério do PBF determina a extrema pobreza como viver com até R\$ 70 de renda familiar por pessoa ao mês, e a pobreza entre R\$ 70 e R\$140. A partir de dados compilados pelo Ipeadata com base na Pesquisa Nacional de Amostra por Domicílios (Pnad), na figura 1, mostra-se a evolução dos indicadores de pobreza e extrema pobreza no Brasil.

Nesse caso, a linha de extrema pobreza foi estimada pelo Ipea com base no valor de uma cesta de alimentos com o mínimo de calorias necessárias para suprir adequadamente uma pessoa, segundo recomendações da Organização das Nações Unidas para a Alimentação e Agricultura e da Organização Mundial da Saúde. A linha de pobreza aqui considerada é o dobro da linha de extrema pobreza. Na figura 1 mostra-se um aumento de aproximadamente $9 \%$ nos dois indicadores de pobreza no período 1999-2003 e uma queda de 57,7\% e 66,5\% na pobreza extrema e pobreza moderada, respectivamente, no período 2004-09.

Figura 1

Número de pessoas em domicílios com renda domiciliar per capita inferior à linha de extrema pobreza e à linha de pobreza

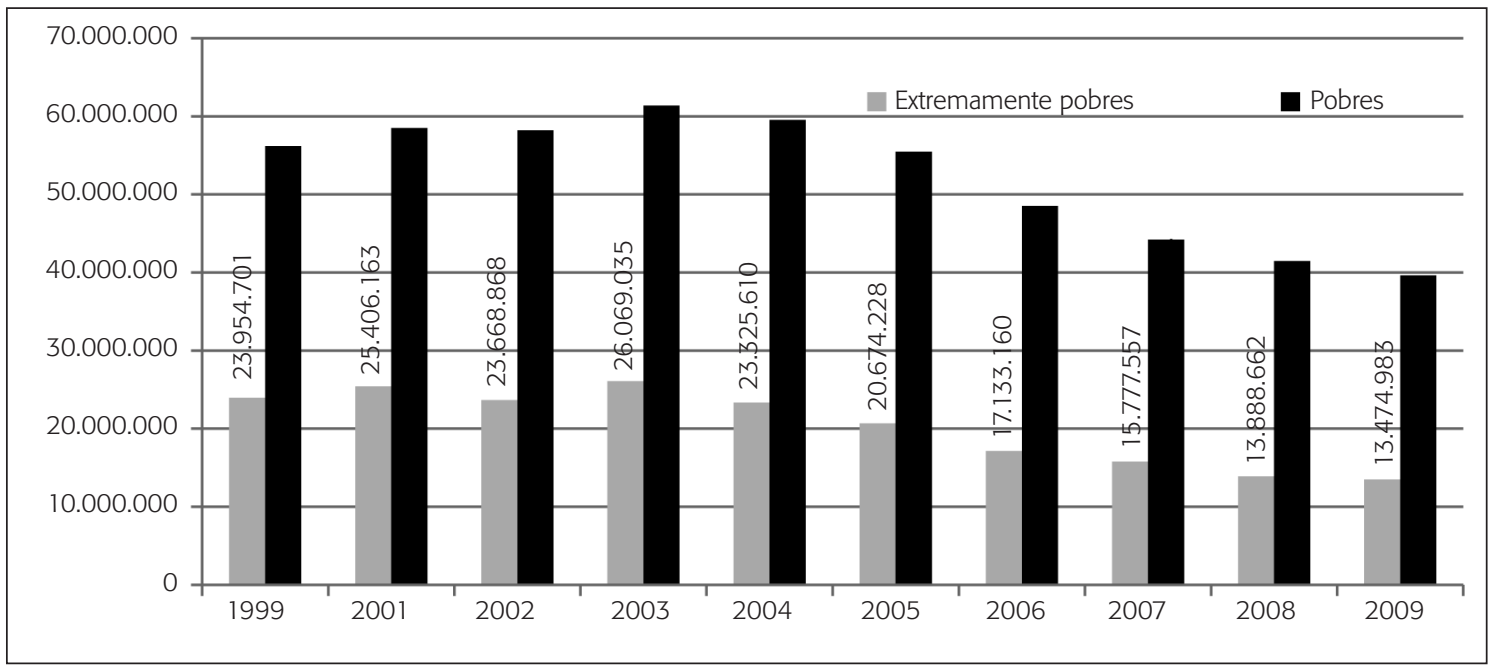

Fonte: Ipeadata (2013) com base nos dados do IBGE/Pnad (1999-2009).

O conceito de pobreza relativa, por sua vez, é baseado na comparação das condições de vida dos indivíduos ou famílias da sociedade. Portanto, a pobreza relativa é a situação dada 
por um nível de vida inferior a um padrão estabelecido para determinada sociedade. Assim, alguns especialistas propuseram que a linha de pobreza fosse definida como um percentil da distribuição da renda, por exemplo, abaixo do $3^{\text {o }}$ decil, conforme ressalta Hoffmann (2006).

Essa medida tem a vantagem de reconhecer que o conjunto de bens e serviços considerados necessários aumenta ao longo do tempo com o desenvolvimento da sociedade. Porém, tem uma distorção: é possível que numa comunidade mais desenvolvida não exista pobreza absoluta, mas, pelo fato de persistir a desigualdade de renda, a pobreza se perpetue. Nesse sentido, o conceito de pobreza relativa se confunde com o conceito de desigualdade de renda.

Na tabela 1 mostra-se a proporção da renda total do Brasil apropriada pelos 10 percentis da distribuição segundo a renda domiciliar per capita calculada pelo Ipea a partir dos dados da Pnad. Observa-se que, mesmo o país tendo passado nos últimos 10 anos por modificações positivas nas características distributivas, a diferença entre os mais pobres e os mais ricos ainda é muito elevada. A renda total do país apropriada pelos 10\% mais ricos em 2009 é equivalente à renda disponível dos $80 \%$ mais pobres da distribuição.

Tabela 1

Proporção da renda total do país apropriada pelos 10 décimos da população segundo a renda domiciliar per capita

\begin{tabular}{|lrrrrrrrrrr|}
\hline & 1999 & 2001 & 2002 & 2003 & 2004 & 2005 & 2006 & 2007 & 2008 & 2009 \\
\hline $10 \circ$ & 47,27 & 47,45 & 47,03 & 46,21 & 45,33 & 45,33 & 44,76 & 43,87 & 43,24 & 42,77 \\
$9 \circ$ & 16,35 & 16,20 & 16,12 & 16,26 & 16,21 & 15,95 & 15,98 & 16,01 & 15,94 & 15,92 \\
80 & 10,46 & 10,44 & 10,46 & 10,61 & 10,68 & 10,62 & 10,63 & 10,81 & 10,84 & 10,90 \\
70 & 7,53 & 7,53 & 7,57 & 7,70 & 7,82 & 7,86 & 7,93 & 8,11 & 8,16 & 8,26 \\
60 & 5,70 & 5,80 & 5,85 & 6,00 & 6,13 & 6,19 & 6,25 & 6,48 & 6,57 & 6,66 \\
$5 \circ$ & 4,45 & 4,45 & 4,50 & 4,59 & 4,73 & 4,78 & 4,88 & 5,04 & 5,15 & 5,23 \\
$4 \circ$ & 3,36 & 3,36 & 3,42 & 3,51 & 3,63 & 3,68 & 3,80 & 3,88 & 4,00 & 4,08 \\
$3 \circ$ & 2,47 & 2,46 & 2,53 & 2,59 & 2,72 & 2,76 & 2,86 & 2,91 & 3,03 & 3,09 \\
$2 \circ$ & 1,67 & 1,64 & 1,74 & 1,76 & 1,89 & 1,93 & 1,99 & 2,02 & 2,10 & 2,13 \\
10 & 0,74 & 0,68 & 0,78 & 0,77 & 0,86 & 0,90 & 0,92 & 0,88 & 0,96 & 0,96 \\
Soma & 100 & 100 & 100 & 100 & 100 & 100 & 100 & 100 & 100 & 100 \\
\hline
\end{tabular}

Fonte: Ipeadata (2013) com base nos dados do IBGE/Pnad (1999-2009).

O conceito de pobreza absoluta e relativa por meio de um limite de rendimento tem sido criticado por Sen $(1989,1997,2000)$. O autor define a pobreza de uma forma mais abrangente: como a incapacidade de um indivíduo alcançar certas condições para satisfazer adequadamente funções consideradas essenciais. Argumenta que a correspondência entre a pobreza vista como falta de renda e a pobreza vista como incapacidade de satisfazer as necessidades essenciais pode falhar. Por exemplo, dois indivíduos, um jovem e um idoso, podem ter o mesmo rendimento, mas o segundo pode ter maiores dificuldades em converter sua renda em capacidade devido às despesas exigidas pelas condições de saúde. Assim, a pobreza pode 
ser mais intensa do que a avaliada pela renda. Consequentemente, o uso de uma linha de pobreza pode ser inadequado para identificar e aferir a pobreza. Neste sentido, Sen (1997) propõe determinar a pobreza em termos de privação de capacidade.

Seguindo a abordagem de Sen, vários índices sintéticos de pobreza multidimensionais surgiram. Por exemplo, a abordagem das necessidades básicas insatisfeitas (NBI) da Cepal, os índices de pobreza humana (IPH-1 e IPH-2) do Programa das Nações Unidas para o Desenvolvimento e o índice de pobreza multidimensional do Brasil, elaborado pelo Ipea. Porém, dadas as restrições das informações dos censos nos países pobres, a principal divergência entre os pesquisadores está em dilemas como: quais as dimensões mais relevantes? Como estimar o valor das variáveis e seus pesos? Qual deve ser o método de agregação das dimensões da pobreza?

Há, também, diversos indicadores de desigualdade na distribuição de renda que são eminentemente relativos. Os indicadores de desigualdade mais utilizados têm sido o coeficiente de Gini e os índices de Theil. Eles são medidas de dispersão da distribuição da renda e medem o grau de concentração ou desigualdade existente na renda domiciliar per capita de um país ou região.

$\mathrm{O}$ coeficiente Gini está associado à curva de Lorenz e varia de 0 a 1 . Zero indica que não há desigualdade, ou seja, a renda de todos os indivíduos tem o mesmo valor. O valor 1 mostra que a desigualdade é máxima, apenas um indivíduo detém toda a renda da sociedade e a renda de todos os outros indivíduos é nula.

O índice Theil está baseado no conceito de entropia de uma distribuição. Toma valor nulo quando não existe desigualdade de renda entre indivíduos e tende a infinito quando a desigualdade tende ao máximo. Existem duas medidas de desigualdade de Theil: Theil-T e Theil-L. Enquanto, no Theil-T os fatores de ponderação da desigualdade dentro dos grupos são dados pela fração da renda apropriada, no Theil-L os fatores de ponderação da desigualdade dentro dos grupos são as populações dos grupos.

A preferência desses indicadores no estudo das políticas de transferência de renda é constatada pelo fato de que eles satisfazem o princípio de Pigou-Dalton. A exigência PigouDalton estabelece que as medidas de desigualdade devem ser sensíveis às transferências de renda entre indivíduos de diferentes classes, como os índices devem aumentar sempre que for feita uma transferência regressiva de renda, ou seja, quando um montante da renda de uma pessoa é subtraído para acrescentá-lo à renda de outra pessoa que no período anterior possuía renda igual ou superior à primeira (Hoffmann, 1998).

No gráfico 2 são apresentados os índices de Gini e Theil-T com base nos dados do Ipeadata. A principal característica observável é a redução desses índices, indicando uma redução das desigualdades de renda no Brasil no período 2001-09. Pode-se inferir que a distribuição da renda brasileira se tornou menos dispersa e heterogênea, confirmando os dados da figura 2. Porém, uma distribuição mais equitativa não necessariamente promove a redução da pobreza. Por exemplo, a equalização da renda em um país com uma renda per capita baixa pode aumentar o número de pessoas abaixo da linha da pobreza. 
Um diagnóstico da dinâmica intradistribuição ao longo do tempo poderá mostrar melhor se a diminuição das desigualdades é acompanhada pela redução da extrema pobreza e da pobreza moderada, ou seja, se a renda do segmento mais pobre da população cresce mais rápido do que a renda dos segmentos mais ricos e, assim, a mobilidade das classes mais pobres aumenta. Isto implica a ideia de convergência na distribuição da renda, que aqui será analisada usando-se a técnica cadeia de Markov.

Figura 2

Índices de Gini e Theil-T de dispersão da distribuição da renda do Brasil

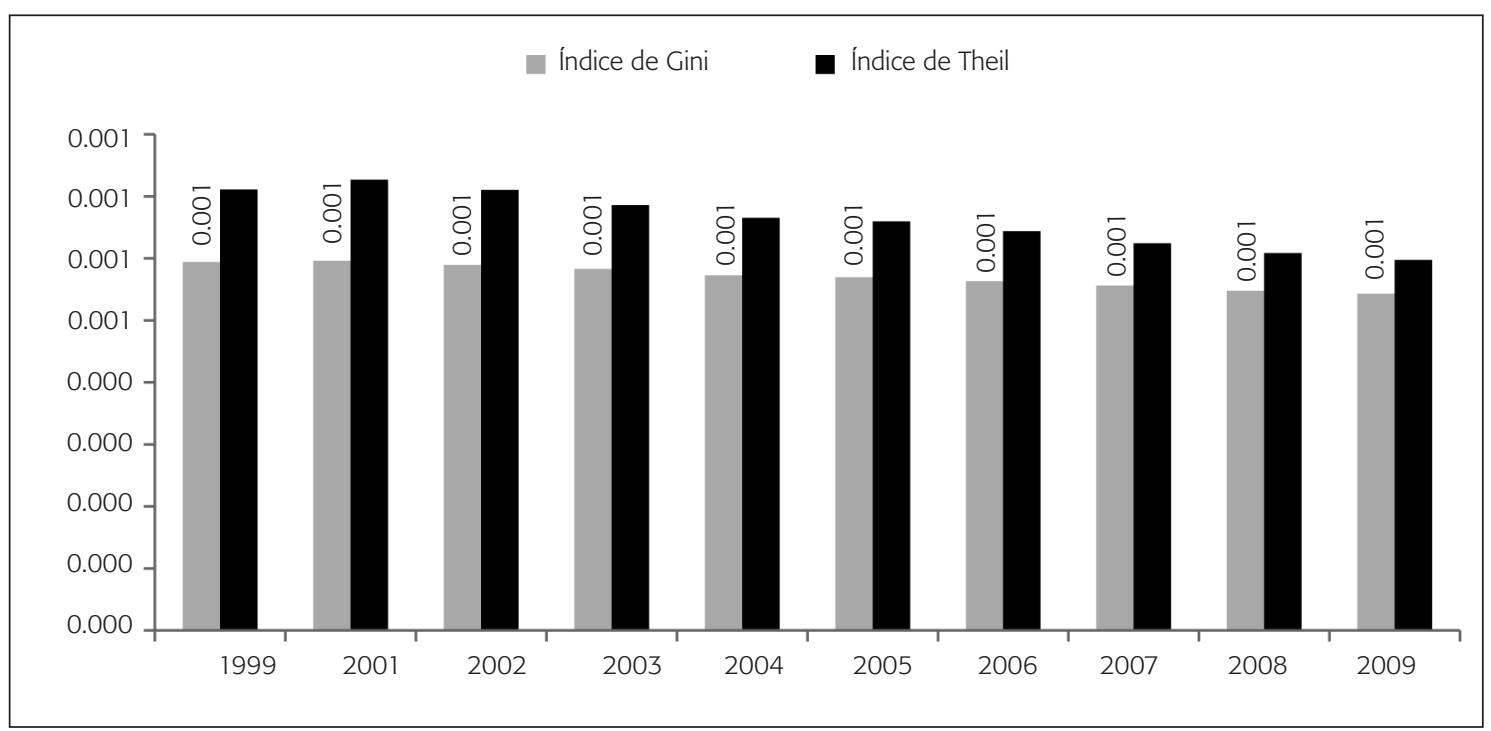

Fonte: Ipeadata (2013) com base nos dados do IBGE/Pnad (1999-2009).

\subsection{0 método cadeia de Markov}

A utilização desse método na análise das tendências da distribuição da renda foi originalmente desenvolvida por Champernowne (1953). Fochezatto e Stülp (2004), Laurini, Andrade e Pereira (2005) e Pôrto Júnior e Ribeiro (2003) são exemplos de trabalhos aplicados sob o método da cadeia de Markov para analisar a evolução das disparidades regionais do Brasil, em vários estados e diferentes aspectos da economia.

Esse método pode ser assim resumido: dado um universo, cada elemento desse conjunto pode encontrar-se em cada instante do tempo em um determinado estado ou classe. O conjunto exaustivo e mutuamente exclusivo desses estados pode ser finito. Por exemplo, considerando a renda da população brasileira e a capacidade de cada indivíduo de satisfazer as funções consideradas essenciais, pode-se classificar os elementos da população em uma determinada categoria social em um dado momento. Desta forma, o espaço de estados $s=(1,2, \ldots, i, j, \ldots, k)$ pode representar as possíveis classes da distribuição de renda nas unidades da federação. Digamos, portanto, que $s=3$ corresponde à classe alta, à classe média e à classe baixa. 
A forma como a distribuição das classes dos elementos da população evolui no tempo é impossível de ser prevista exatamente. Porém, podem-se especificar probabilidades para os possíveis estados em cada instante, partindo-se do princípio de que, se conhecendo a história da evolução até o momento atual, o estado presente resume toda a informação relevante para descrever a probabilidade do estado futuro. Nesse sentido, a distribuição dos possíveis estados da população em pontos discretos do tempo $(\mathrm{t}=0,1,2, \ldots, n)$ forma um vetor (ou variável) aleatório $\left(X_{t}^{s}\right)$ e a sucessão desses vetores forma um processo estocástico.

A cadeia de Markov de primeira ordem consiste em um tipo especial de processo estocástico no qual, dada a distribuição dos estados $X_{1}^{s}, X_{2}^{s}, \ldots, X_{n-1}^{s}$ no tempo t, as probabilidades dos estados do vetor futuro $X_{n}$ dependem apenas da ocorrência imediatamente anterior $X_{n-1}^{s}$. Assim:

dado $\left\{X_{t}^{s}\right\}=\left\{x_{t}^{1}, x_{t}^{2}, \ldots, x_{t}^{i}, x_{t}^{j}, \ldots, x_{t}^{k}\right\}$

$P\left(X_{n}=\left|x_{n}^{j}\right| X_{0}=x_{0}^{s}, X_{1}=x_{1}^{s}, \ldots, X_{n-1}=x_{n-1}^{i}\right)=P\left(X_{n}=x_{n}^{j} \mid X_{n-1}=x_{n-1}^{i}\right)=P_{i j}$

As probabilidades condicionadas $P\left(X_{n}=x_{n}^{j} \mid X_{n-1}=x_{n-1}^{i}\right)=P_{i j}$ são as probabilidades de transição, ou seja, a probabilidade futura de uma classe do vetor $X_{n}^{s}$ estar no estado $j$ no instante $n$ dado que o vetor presente $X_{n-1}^{s}$ está no estado $i$ no instante $n-1$. Desta forma, as $\mathrm{k} \times \mathrm{k}$ probabilidades podem ser representadas através da matriz de transição $\mathbf{P}$ :

$\mathrm{P}=\left(\begin{array}{ccccc}p_{11} & p_{12} & p_{13} & \cdots & p_{1 k} \\ p_{21} & p_{22} & p_{23} & \cdots & p_{2 k} \\ \vdots & \vdots & \vdots & & \vdots \\ p_{k 1} & p_{k 2} & p_{k 3} & \cdots & p_{k k}\end{array}\right)$

A matriz de transição segue as propriedades de que todas as suas probabilidades de transição $0 \leq \mathrm{P}_{\mathrm{ij}} \leq 1$ são fixas (estacionárias ao longo do tempo) e a soma de cada uma das linhas de $\mathbf{P}$ deverá totalizar 1 . Assim, em termos matemáticos, esta condição é expressa como: $\forall j \in s, \sum_{i \in s} P_{i j}=1$.

Para definir a dinâmica subjacente a um processo markoviano usa-se o vetor inicial (a primeira frequência de classes de renda), ou seja, a fração de uma população de tamanho $N$ que está no estado "s" no período inicial $\mathrm{t}=0$. Essa condição é expressa como: $\left(\mathrm{X}_{0}^{\mathrm{s}}\right)$. Cabe notar que a estimação das probabilidades de transição por meio de frequências relativas é motivada devido à lei dos grandes números. Assim, a distribuição de frequência dos estados no tempo $t=1$ é calculada e expressa por meio da seguinte expressão matemática:

$$
\left(\begin{array}{c}
x_{1}^{1} \\
\cdot \\
\cdot \\
x_{1}^{k}
\end{array}\right)=\left(\begin{array}{ccc}
P_{11} & \ldots & P_{1 k} \\
\cdot & \ldots & \cdot \\
\cdot & \ldots & \cdot \\
\cdot & \ldots & \cdot \\
P_{k 1} & \ldots & P_{k k}
\end{array}\right)\left(\begin{array}{c}
x_{0}^{1} \\
\cdot \\
\cdot \\
\cdot \\
x_{0}^{k}
\end{array}\right)=X_{1}^{s}=P X_{0}^{s}
$$


Usando-se a equação de Kolmogorov-Chapman pode-se calcular a distribuição dos estados de $X_{t}^{s}$ (ou seja, os estados de uma população de tamanho N no período "t") após n transições da seguinte maneira:

$$
\left(\begin{array}{c}
x_{n}^{1} \\
\cdot \\
\cdot \\
x_{n}^{k}
\end{array}\right)=\left(\begin{array}{ccc}
P_{11} & \ldots & P_{1 k} \\
\cdot & \ldots & \cdot \\
\cdot & \ldots & \cdot \\
\cdot & \ldots & \cdot \\
P_{k 1} & \ldots & P_{k k}
\end{array}\right)\left(\begin{array}{c}
x_{0}^{1} \\
\cdot \\
\cdot \\
\cdot \\
x_{0}^{k}
\end{array}\right)=X_{n}^{s}=P^{n} X_{0}^{s}
$$

À medida que se aumenta o número de transições, o processo de Markov tenderá para um equilíbrio estacionário único, de forma que a distribuição de equilíbrio não dependa da distribuição inicial.

Além disso, dada a matriz de transição $\mathbf{P}$, mostrada anteriormente na expressão (2), podem-se obter diferentes índices comparativos de mobilidade, que identificam a dinâmica intradistribuição da renda. Esses índices consideram as probabilidades de transição entre as classes, dadas pelos elementos situados fora da diagonal principal da matriz, e situam-se entre duas ocorrências extremas. No primeiro caso extremo, resulta uma matriz de transição identidade, com probabilidades de permanência iguais a um, o que identifica uma sociedade com perpetuidade perfeita, ou seja, não mobilidade entre as classes de renda. No caso oposto, a matriz $\mathbf{P}$ tem todas as linhas idênticas e o traço igual a zero, o que determina uma tendência para uma distribuição variante, na qual todas as classes têm a mesma oportunidade. Portanto, há uma mobilidade perfeita.

A partir destes princípios descritos por Prais (1955) e Shorrocks (1978) define-se o índice:

$\mathrm{M}(\mathbf{P})=\frac{k-\operatorname{tr}(P)}{k-1}$

Onde $\operatorname{tr}(\mathbf{P})$ representa o traço e $k$ a ordem da matriz quadrada de transição. Quanto maior a probabilidade de permanência em um mesmo estado, maior será o valor do traço e, portanto, menor o índice.

\subsection{0 método diferenças em diferenças}

O método diferenças em diferenças também conhecido como diff-in-diffs (DD), conforme Blundell e Dias (2000), é geralmente utilizado para a avaliação de políticas públicas. Essa abordagem considera uma reforma política como um experimento e tenta encontrar uma ocorrência natural de comparação que pode simular as propriedades do grupo de controle. 
Como pode ser percebido na tabela 2 , isso ocorre por meio da comparação entre o comportamento da variável dependente para o grupo de tratamento e o grupo de controle, antes e depois da implementação da política pública.

Tabela 2

\section{Método diferenças em diferenças}

\begin{tabular}{|ccc|}
\hline Período & $\begin{array}{c}\text { Grupo afetado pela política pública } \\
\text { (grupo de tratamento) }\end{array}$ & $\begin{array}{c}\text { Grupo não afetado pela política pública } \\
\text { (grupo de controle) }\end{array}$ \\
\hline Depois do programa & $Y_{7}\left(u_{i}\right) \mid D_{i}=1$ & $Y_{l}\left(u_{i}\right) \mid D_{i}=0$ \\
Antes do Programa & $Y_{0}\left(u_{i}\right) \mid D_{i}=1$ & $Y_{0}\left(u_{i}\right) \mid D_{i}=0$ \\
Depois - Antes & $\left(Y_{l} \mid D=1\right)-\left(Y_{0} \mid D=1\right)$ & $\left(Y_{l} \mid D=0\right)-\left(Y_{0} \mid D=0\right)$ \\
& $\left.D D=\left[\left(Y_{l} \mid D=1\right)-Y_{0} \mid D=1\right)\right]-\left[\left(Y_{l} \mid D=0\right)-\left(Y_{0} \mid D=0\right)\right]$ \\
\hline
\end{tabular}

Fonte: Gertler e colaboradores (2011).

No gráfico 1 representa-se o método DD para um grupo de tratamento, ou seja, para o grupo afetado pela política pública e um grupo de controle não afetado.

\section{Gráfico 1 \\ O método diferenças em diferenças}

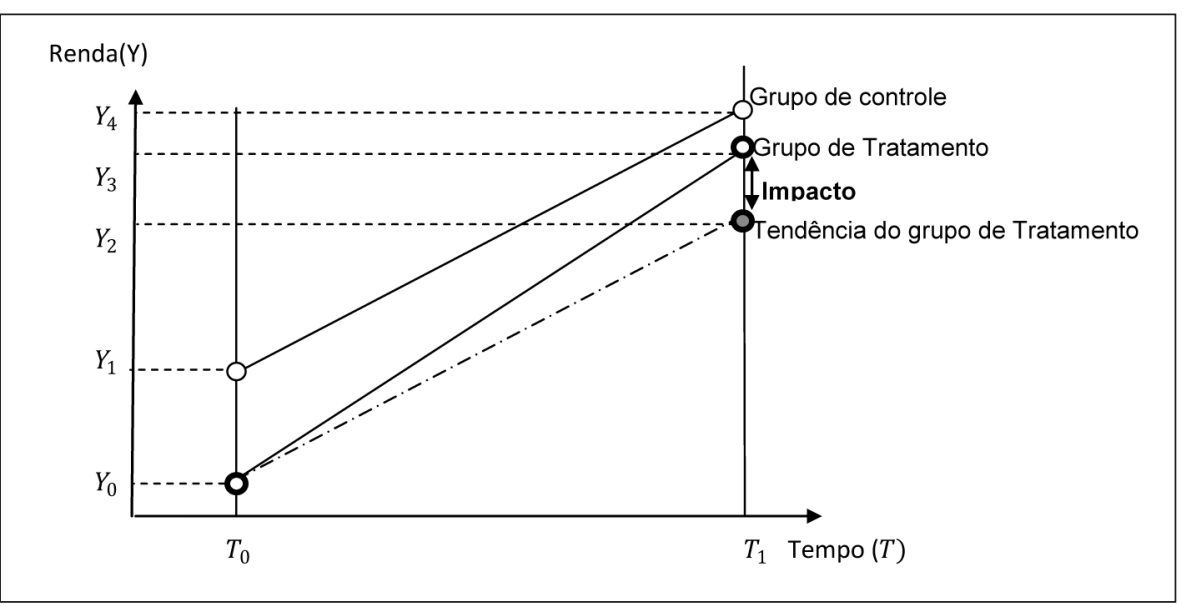

Fonte: Elaboração dos autores.

Observa-se que no gráfico 1 no período $\mathrm{T}_{0}$ o grupo de controle e o grupo de tratamento apresentam rendas diferentes, respectivamente $\mathrm{Y}_{1}$ e $\mathrm{Y}_{0}$. No período $\mathrm{T}_{1}$ o grupo afetado pela política pública, ou o grupo de tratamento, apresenta uma tendência de renda diferente da tendência do grupo de controle. A diferença entre essa renda encontrada e a tendência de renda para o grupo de tratamento é o impacto da política pública.

Segundo Cameron e Trivedi (2005), o cálculo do DD pode ser simplificado por meio de um modelo estatístico de regressão na forma: 
$\mathrm{y}=\beta_{0}+\beta_{1} \mathrm{~S}+\beta_{2} \mathrm{~T}+\beta_{3} \mathrm{ST}$

Onde $S$ é uma variável dummy, ou seja, é uma variável binária assumindo o valor igual a 1 quando o grupo é afetado pela política pública e igual a 0 quando não. Assim, T é uma variável dummy que assume 1 no período pós-impacto e 0 antes do impacto da política e $S T$ é uma variável dummy que assume valor igual a 1 para todos os grupos afetados pela política pública no último período.

\section{Parâmetros e resultados da análise dos métodos cadeia de Markov e diferenças em diferenças}

Para analisar as tendências e a mobilidade intradistribuição da renda antes e depois do PBF, inicialmente aplicou-se o método cadeia de Markov, utilizando-se os dados da renda média domiciliar per capita por décimos da população das unidades da federação nos anos 1999, 2003, 2005 e 2009. Esses dados foram originalmente calculados pelo Ipea em valores reais a partir dos dados da Pnad/IBGE.

Por não haver um consenso na literatura sobre uma forma única de se calcular a amplitude de classes de distribuição da renda, conforme enfatiza Fochezatto (2004), optou-se pelo critério utilizado a partir do Ipeadata que divide os dados em 10 grupos com o mesmo número de pessoas. Assim, com base nos valores da renda média domiciliar per capita por décimo da população do Brasil, foi possível definir os pontos de corte e o vetor inicial, conforme apresentado na tabela 3. Observa-se que as últimas três classes de renda ( $\mathrm{H}, \mathrm{I}$ e, J) contemplam as classes da pobreza moderada, intermediária e extrema, respectivamente, segundo os critérios próximos àqueles adotados pelo Bolsa Família.

\section{Tabela 3}

Renda domiciliar per capita média por décimo da população (R\$ de out. 2009)

\begin{tabular}{|ccr|}
\hline Classe & Frequência & \multicolumn{1}{c|}{ Média } \\
\hline A & $10 \%$ & $2.664,42$ \\
B & $10 \%$ & 921,27 \\
C & $10 \%$ & 589,36 \\
D & $10 \%$ & 424,24 \\
E & $10 \%$ & 321,38 \\
F & $10 \%$ & 250,99 \\
G & $10 \%$ & 189,61 \\
H & $10 \%$ & 139,11 \\
I & $10 \%$ & 93,95 \\
J & $10 \%$ & 41,60 \\
\hline
\end{tabular}

Fonte: Ipeadata (2013). 
As distribuições das rendas domiciliares per capita médias das 27 unidades da federação dos quatro anos $(1999,2003,2005,2009)$ em 10 níveis foram utilizadas para gerar as matrizes de probabilidade de transição correspondentes a dois momentos: antes e depois da implantação do programa Bolsa Família, ou seja, os períodos 1999-2003 e 2005-09. Nos primeiros quatro anos, observou-se um número grande de programas de transferências de renda com iniciativas isoladas, objetivos e públicos diferentes. Nos anos seguintes, o PBF ganhou maior destaque. Convém ressaltar que, metodologicamente, o mesmo intervalo de tempo é essencial na comparação do impacto e tendências de políticas públicas.

\subsection{Período anterior ao Programa Bolsa Família}

Conforme já explicado anteriormente, o método cadeias de Markov pode ser aplicado para prever a probabilidade de uma classe de elementos de um conjunto mudar de estado em um momento futuro, conhecendo-se o estado inicial desta classe.

A matriz de transição do período anterior à implementação do Programa Bolsa Família é mostrada na tabela 4. Seus elementos representam a chance de os indivíduos que estavam em uma determinada classe no ano 1999 permanecerem ou migrarem para outra classe no ano 2003, ou seja, a probabilidade de transição. As três últimas linhas e colunas da matriz $(\mathrm{H}$, $\mathrm{I}$, e J) representam, respectivamente, as classes de pobreza moderada, pobreza intermediária e extrema pobreza.

A matriz mostra que não existem estados absorventes, ou seja, não há certeza, em nenhuma das classes de renda, de permanência no estado inicial no período seguinte $(p \neq 1)$. A maior probabilidade é dada pelo elemento $p_{J J}=92,86 \%$ (ver linha $J$, coluna $J$ ), que indica a chance daquele extrato de $10 \%$ da população que estava na classe j permanecer nesse estado, com apenas 7,14\% de probabilidade de melhorar a situação no período seguinte. Esse é o pior caso já que representa a classe de extrema pobreza.

A segunda maior probabilidade de permanência é $p_{H H}=92 \%$, mostrando que existe apenas $4 \%$ de chance de passar da pobreza moderada para a classe seguinte superior, e $4 \%$ de cair no nível intermediário de pobreza. Isso adverte a respeito da existência de insuficientes oportunidades para que os brasileiros mais pobres melhorem sua condição de vida.

Na tabela 5 encontram-se os valores da distribuição inicial dos dados e a solução do sistema, usando a matriz de transição anterior, para $n=10,20, \ldots, 100$ períodos à frente, até chegar ao steady state, ou seja, à probabilidade de estados em equilíbrio estacionário. Observa-se que nessa solução de equilíbrio confirma-se a existência de tendências redutíveis de homogeneização, ou seja, o número inicial de classes se reduz, desaparecendo as classes mais ricas. Esse resultado está em consonância com a queda dos índices de desigualdade mostrado na figura 2. 
Tabela 4

Matriz de transição do nível médio de renda domiciliar per capita 1999-2003

\begin{tabular}{|c|c|c|c|c|c|c|c|c|c|c|c|}
\hline & \multicolumn{11}{|c|}{ Estado (classes) no próximo período } \\
\hline & & A & B & C & D & $\mathrm{E}$ & $\mathrm{F}$ & G & $\mathrm{H}$ & I & $\mathrm{J}$ \\
\hline \multirow{10}{*}{$\begin{array}{c}\text { Estado } \\
\text { (classes) } \\
\text { no período } \\
\text { inicial }\end{array}$} & A & 0,9189 & 0,0811 & 0,0000 & 0,0000 & 0,0000 & 0,0000 & 0,0000 & 0,0000 & 0,0000 & 0,0000 \\
\hline & B & 0,0000 & 0,6500 & 0,3500 & 0,0000 & 0,0000 & 0,0000 & 0,0000 & 0,0000 & 0,0000 & 0,0000 \\
\hline & C & 0,0000 & 0,0435 & 0,7826 & 0,1739 & 0,0000 & 0,0000 & 0,0000 & 0,0000 & 0,0000 & 0,0000 \\
\hline & D & 0,0000 & 0,0000 & 0,0000 & 0,8000 & 0,1600 & 0,0400 & 0,0000 & 0,0000 & 0,0000 & 0,0000 \\
\hline & E & 0,0000 & 0,0000 & 0,0000 & 0,1667 & 0,5833 & 0,2500 & 0,0000 & 0,0000 & 0,0000 & 0,0000 \\
\hline & $\mathrm{F}$ & 0,0000 & 0,0000 & 0,0000 & 0,0000 & 0,1935 & 0,6129 & 0,1935 & 0,0000 & 0,0000 & 0,0000 \\
\hline & G & 0,0000 & 0,0000 & 0,0000 & 0,0000 & 0,0000 & 0,1818 & 0,6970 & 0,1212 & 0,0000 & 0,0000 \\
\hline & $\mathrm{H}$ & 0,0000 & 0,0000 & 0,0000 & 0,0000 & 0,0000 & 0,0000 & 0,0400 & 0,9200 & 0,0400 & 0,0000 \\
\hline & 1 & 0,0000 & 0,0000 & 0,0000 & 0,0000 & 0,0000 & 0,0000 & 0,0000 & 0,1053 & 0,8684 & 0,0263 \\
\hline & $\mathrm{J}$ & 0,0000 & 0,0000 & 0,0000 & 0,0000 & 0,0000 & 0,0000 & 0,0000 & 0,0000 & 0,0714 & 0,9286 \\
\hline
\end{tabular}

Fonte: Cálculo dos autores.

Além disso, nota-se que as classes remanescentes de renda não formam estados (clubes) fechados. Verifica-se, portanto, que todos eles são acessíveis, se comunicam, ou seja, existe mobilidade tanto para melhoria quanto para piora social, não havendo convergência ou equalização social para um padrão único de renda no longo prazo. Esse resultado é decorrente dos valores da diagonal principal da matriz de transição mostrada na tabela 4. Por exemplo, seja a linha I e a coluna I (pobreza intermediária), com probabilidade de permanência $p_{I I}=86,84 \%$. Há probalidade de melhoria social igual a 10,53\% e de piora igual a 2,63\%. Por outro lado, na classe de renda $\mathrm{D}\left(p_{D D}=80 \%\right)$ há probalidade de melhoria igual a $0 \%$ e de piora social igual a $16 \%$. Assim, se a tendência observada no período analisado se mantiver, o vetor de steady state fornece a probabilidade de longo prazo de um brasileiro ocupar uma das sete categorias de renda. Porém, conforme pode ser conferido na tabela 5, é importante resaltar que a redução das disparidades de renda concentra-se no estado da pobreza moderada. Essa classe, $\mathrm{H}$, é a que mais cresceu (de uma distribuição inicial igual a 10\% para 39,24\% em estado estacionário) em correspondência com os dados da figura 1 , e isso se dá em razão da redução da participação nas classes A, B, C, D, E e J.

A tabela 5 evidencia também que o número de períodos necessários para se chegar até o equilíbrio de longo prazo é superior a 100, equivalente a 400 anos, considerando que cada transição equivale a um intervalo composto de quatro anos. Observe que é somente nesse período que o vetor de estado estacionário apresenta valores iguais a $0 \%$ para as três classes mais altas.

Outro resultado direto da solução do sistema de equações, mostrado na tabela 4, é a determinação do número esperado de períodos para retornar ao estado atual, chamado tempo médio de recorrência ( $1 / \pi)$. Assim, mesmo que os brasileiros da classe de pobreza moderada H tenham uma chance de 60,79\% (100-39,24) de sair desse estado, serão necessários apro- 
ximadamente 2,55 períodos ( $4 \times 2,55=10,2$ anos) para que eles voltem ao clube da pobreza moderada. Isso determina a perpetuidade da miséria (ciclo de pobreza).

Tabela 5

Frequências observadas e estimadas para os anos 1999-2003

\begin{tabular}{|c|c|c|c|c|c|c|c|c|c|}
\hline \multirow{2}{*}{$\begin{array}{l}\text { Estado } \\
\text { (clube) }\end{array}$} & \multirow{2}{*}{$\begin{array}{l}\text { Distribuição } \\
\text { inicial }\end{array}$} & \multicolumn{6}{|c|}{ Número de transições (anos) } & \multirow{2}{*}{$\begin{array}{c}\text { Estado } \\
\text { estacionário }(\pi)\end{array}$} & \multirow{2}{*}{$\begin{array}{l}\text { Tempo } \\
\text { médio de } \\
\text { recorrência } \\
(1 / \pi)\end{array}$} \\
\hline & & $\begin{array}{c}10 \\
(2043)\end{array}$ & $\begin{array}{c}20 \\
(2083)\end{array}$ & $\begin{array}{c}40 \\
(2163)\end{array}$ & $\begin{array}{c}60 \\
(2243)\end{array}$ & $\begin{array}{c}80 \\
(2323)\end{array}$ & $\begin{array}{c}100 \\
(2403)\end{array}$ & & \\
\hline A & $10 \%$ & $4,29 \%$ & $1,84 \%$ & $0,34 \%$ & $0,06 \%$ & $0,01 \%$ & $0,00 \%$ & $0,00 \%$ & infinito \\
\hline B & $10 \%$ & $2,39 \%$ & $0,98 \%$ & $0,18 \%$ & $0,03 \%$ & $0,01 \%$ & $0,00 \%$ & $0,00 \%$ & infinito \\
\hline C & $10 \%$ & $6,43 \%$ & $2,60 \%$ & $0,46 \%$ & $0,08 \%$ & $0,02 \%$ & $0,00 \%$ & $0,00 \%$ & infinito \\
\hline $\mathrm{D}$ & $10 \%$ & $16,01 \%$ & $13,93 \%$ & $10,18 \%$ & $8,42 \%$ & $7,63 \%$ & $7,26 \%$ & $6,93 \%$ & 14,44 \\
\hline E & $10 \%$ & $11,91 \%$ & $12,53 \%$ & $10,99 \%$ & $9,69 \%$ & $8,98 \%$ & $8,64 \%$ & $8,31 \%$ & 12,03 \\
\hline $\mathrm{F}$ & $10 \%$ & $13,37 \%$ & $15,26 \%$ & $14,82 \%$ & $13,64 \%$ & $12,91 \%$ & $12,53 \%$ & $12,17 \%$ & 8,22 \\
\hline G & $10 \%$ & $10,20 \%$ & $12,57 \%$ & $13,85 \%$ & $13,61 \%$ & $13,32 \%$ & $13,14 \%$ & $12,95 \%$ & 7,72 \\
\hline $\mathrm{H}$ & $10 \%$ & $19,45 \%$ & $25,44 \%$ & $33,23 \%$ & $36,69 \%$ & $38,12 \%$ & $38,73 \%$ & $39,24 \%$ & 2,55 \\
\hline I & $10 \%$ & $9,35 \%$ & $9,84 \%$ & $11,71 \%$ & $13,21 \%$ & $14,05 \%$ & $14,49 \%$ & $14,91 \%$ & 6,71 \\
\hline J & $10 \%$ & $6,59 \%$ & $4,98 \%$ & $4,25 \%$ & $4,57 \%$ & $4,95 \%$ & $5,21 \%$ & $5,49 \%$ & 18,21 \\
\hline
\end{tabular}

Fonte: Cálculo dos autores.

Nesse cenário, pode-se afirmar que os programas governamentais de transferência de renda em execução neste período (1999-2003) eram insuficientes para impactar de maneira positiva a redução da pobreza, pois, de acordo com os resultados expostos, há significativas chances de piora para classes mais baixas de renda, além de ausência de convergência para as classes mais promissoras. Assim, pode-se rejeitar a hipótese de eficácia das políticas de transferência de renda nesse período.

\subsection{Período posterior ao Programa Bolsa Família}

A matriz de transição do período posterior à implementação do Programa Bolsa Família é mostrada na tabela 6. Diferentemente da matriz anterior, ela mostra que existe um estado absorvente: a classe A com uma probabilidade de 100\% de permanência no estado de maior nível de renda média — $\mathrm{R} \$ 2.664,42$. Além disso, as probabilidades de permanência nas classes mais pobres são menores e oferecem chances de melhoria maiores, evidenciando que a tendência das classes empobrecidas de permanecerem "aprisionadas" na chamada armadilha da pobreza é mais fraca do que no período anterior. Reforçando essa tendência de melhoria, a matriz também tem um peso relativo maior na parte inferior da diagonal principal. Observe que na classe de renda I que espelha a pobreza intermediária a probabilidade de permanência 
no estado inicial é dada por $p_{I I}=51,6 \%$. A probabilidade de melhoria é igual a 48,4\% e de piora social igual a $0 \%$. Na classe $\mathrm{J}$, de pobreza extrema, há probabilidade de melhoria social igual a $66,7 \%$.

Tabela 6

Matriz de transição do nível médio de renda domiciliar per capita - 2005-09

\begin{tabular}{|c|c|c|c|c|c|c|c|c|c|c|c|}
\hline & \multicolumn{11}{|c|}{ Estado (classes) no próximo período } \\
\hline & & A & B & $\mathrm{C}$ & $\mathrm{D}$ & E & $\mathrm{F}$ & G & $\mathrm{H}$ & I & J \\
\hline \multirow{10}{*}{$\begin{array}{c}\text { Estado } \\
\text { (classes) } \\
\text { no período } \\
\text { inicial }\end{array}$} & A & 1,000 & 0,000 & 0,000 & 0,000 & 0,000 & 0,000 & 0,000 & 0,000 & 0,000 & 0,000 \\
\hline & B & 0,500 & 0,500 & 0,000 & 0,000 & 0,000 & 0,000 & 0,000 & 0,000 & 0,000 & 0,000 \\
\hline & C & 0,000 & 0,615 & 0,385 & 0,000 & 0,000 & 0,000 & 0,000 & 0,000 & 0,000 & 0,000 \\
\hline & $\mathrm{D}$ & 0,000 & 0,154 & 0,769 & 0,077 & 0,000 & 0,000 & 0,000 & 0,000 & 0,000 & 0,000 \\
\hline & $E$ & 0,000 & 0,000 & 0,222 & 0,778 & 0,000 & 0,000 & 0,000 & 0,000 & 0,000 & 0,000 \\
\hline & $\mathrm{F}$ & 0,000 & 0,000 & 0,000 & 0,250 & 0,679 & 0,071 & 0,000 & 0,000 & 0,000 & 0,000 \\
\hline & G & 0,000 & 0,000 & 0,000 & 0,000 & 0,242 & 0,667 & 0,091 & 0,000 & 0,000 & 0,000 \\
\hline & $\mathrm{H}$ & 0,000 & 0,000 & 0,000 & 0,000 & 0,000 & 0,100 & 0,700 & 0,200 & 0,000 & 0,000 \\
\hline & I & 0,000 & 0,000 & 0,000 & 0,000 & 0,000 & 0,000 & 0,000 & 0,484 & 0,516 & 0,000 \\
\hline & J & 0,000 & 0,000 & 0,000 & 0,000 & 0,000 & 0,000 & 0,000 & 0,000 & 0,667 & 0,333 \\
\hline
\end{tabular}

Fonte: Cálculo dos autores.

Na tabela 7 encontram-se os valores da distribuição inicial dos dados e a solução do sistema, utilizando-se a matriz de transição 2005-2009, para $n=1,2,3,4,5$ e 15 períodos à frente.

Na tabela 7 observa-se que a solução de equilíbrio confirma a existência de tendências de convergência para um padrão único de renda no longo prazo, ou seja, há homogeneização. Isso significa que o número inicial de classes se reduz para um, desaparecendo as classes mais pobres. Isso se explica pela alta probabilidade de melhoria em todas as classes, como se pode observar na matriz de transição 2005-09. Esse resultado está em consonância com a queda dos índices de desigualdades mostrados na figura 2.

Na tabela 7 evidencia-se também que o número de períodos para se chegar até o equilíbrio de longo prazo (estado estacionário) é menor do que o anterior. Agora são necessários aproximadamente 15 períodos de quatro anos.

Com relação a isso é importante frizar que nas tabelas 7 e 8 é mostrada uma mesma dinâmica para duas situações iniciais diferentes: na tabela 7 é mostrada a matriz de transição no período posterior ao Programa Bolsa Família com vetor inicial no ano de 1999 (anterior à implantação do programa) e na tabela 8 a mesma matriz é contrastada com o vetor inicial no ano de 2005, posterior à implantação do programa. A finalidade desse contraste reside em comparar o impacto dessa política pública partindo-se de dois cenários diferentes. 
Tabela 7

Frequências observadas e estimadas para os anos 2005-09

(vetor inicial no ano de 1999)

\begin{tabular}{|c|c|c|c|c|c|c|c|c|c|}
\hline \multirow[b]{2}{*}{$\begin{array}{l}\text { Estado } \\
\text { (clube) }\end{array}$} & \multirow[b]{2}{*}{$\begin{array}{l}\text { Distribui- } \\
\text { ção inicial }\end{array}$} & \multicolumn{6}{|c|}{ Número de transições (anos) } & \multirow[b]{2}{*}{$\begin{array}{c}\text { Estado } \\
\text { estacionário }(\pi)\end{array}$} & \multirow{2}{*}{$\begin{array}{l}\text { Tempo } \\
\text { médio de } \\
\text { recorrência } \\
\quad(1 / \pi)\end{array}$} \\
\hline & & $\begin{array}{c}1 \\
(2013)\end{array}$ & $\begin{array}{c}2 \\
(2017)\end{array}$ & $\begin{array}{c}3 \\
(2021)\end{array}$ & $\begin{array}{c}4 \\
(2025)\end{array}$ & $\begin{array}{c}5 \\
(2029)\end{array}$ & $\begin{array}{c}15 \\
(2069)\end{array}$ & & \\
\hline A & $10 \%$ & $15,00 \%$ & $21,35 \%$ & $29,60 \%$ & $39,38 \%$ & $49,70 \%$ & $98,68 \%$ & 1 & 1 \\
\hline B & $10 \%$ & $12,69 \%$ & $16,51 \%$ & $19,56 \%$ & $20,63 \%$ & $19,71 \%$ & $1,07 \%$ & 0 & infinito \\
\hline C & $10 \%$ & $13,76 \%$ & $15,84 \%$ & $15,56 \%$ & $13,68 \%$ & $11,17 \%$ & $0,18 \%$ & 0 & infinito \\
\hline $\mathrm{D}$ & $10 \%$ & $11,05 \%$ & $10,11 \%$ & $8,33 \%$ & $6,35 \%$ & $5,21 \%$ & $0,03 \%$ & 0 & infinito \\
\hline$E$ & $10 \%$ & $9,21 \%$ & $7,60 \%$ & $5,78 \%$ & $4,61 \%$ & $4,12 \%$ & $0,01 \%$ & 0 & infinito \\
\hline $\mathrm{F}$ & $10 \%$ & $8,38 \%$ & $6,56 \%$ & $4,85 \%$ & $4,53 \%$ & $3,55 \%$ & $0,01 \%$ & 0 & infinito \\
\hline G & $10 \%$ & $7,91 \%$ & $5,51 \%$ & $5,46 \%$ & $4,31 \%$ & $2,86 \%$ & $0,01 \%$ & 0 & infinito \\
\hline $\mathrm{H}$ & $10 \%$ & $6,84 \%$ & $7,09 \%$ & $5,45 \%$ & $3,53 \%$ & $2,08 \%$ & $0,00 \%$ & 0 & infinito \\
\hline I & $10 \%$ & $11,83 \%$ & $8,33 \%$ & $5,04 \%$ & $2,85 \%$ & $1,55 \%$ & $0,00 \%$ & 0 & infinito \\
\hline J & $10 \%$ & $3,33 \%$ & $1,11 \%$ & 0,37\% & $0,12 \%$ & $0,04 \%$ & $0,00 \%$ & 0 & infinito \\
\hline
\end{tabular}

Fonte: Cálculo dos autores.

Portanto, para entender melhor o impacto futuro das tendências impostas no período 2005-09 mudou-se posteriormente o vetor inicial adotando-se a frequência no ano de 2005. Na tabela 8 encontram-se os resultados do cálculo do sistema, utilizando-se a matriz de transição do período 2005-09, para $n=1,2,4,6,10$ e 15 períodos à frente, até chegar à probabilidade de estado em equilíbrio estacionário. Com o vetor inicial no ano de 2005 é necessário um número similar de transições para se atingir o estado estacionário: aproximadamente 15, equivalente a 60 anos (4 intervalos de tempo $\times 15$ períodos de transição).

Além disso, os resultados mostram que em apenas 40 anos (10 transições) a proporção de pobres será praticamente igual a zero (0,08\%), ou seja, a partir de 2005, pode-se vislumbrar a perspectiva de mitigar a pobreza no Brasil, se a tendência observada no contexto dos dados utilizados para análise for mantida. Dessa forma, o país teria um número menor de pobres no período posterior ao ano de 2005 (isto é, em 2013), passando de 25,9\% na distribuição inicial em $2005(11,1 \%+11,5 \%+3,3 \%$, que é igual à soma dos percentuais de cada classe de pobreza na coluna distribuição inicial na tabela 8) para uma proporção de pobres igual a 17,04\% da população. Além disso, de acordo com os resultados obtidos, a exterma pobreza (estado J) tem a chance de desaparecer a partir de 2025.

Outro resultado relevante é a determinação dos índices de mobilidade das matrizes de transição, os quais determinam a dinâmica intradistribuição de renda, conforme fora descrito na equação 5. Para o período, anterior ao Bolsa Família (1999-2003), calculou-se um índice igual 0,22 e para o período posterior (2005-09) esse índice foi igual a 0,68. Esse resultado indica que a estrutura social brasileira apresentava uma relativa rigidez no primeiro período. Ou seja, o es- 
trato de renda no qual o indivíduo estava inserido era mais importante para a sua posição futura. Por outro lado, isto mudou um pouco após a implantação do PBF, quando observou-se uma maior mobilidade entre as classes de renda, estando em correspondência com o menor tempo para a convergência. Veja que, de acordo com o que fora exposto a respeito na equação 5, quanto maior a probabilidade de permanência em um mesmo estado, menor será o índice obtido.

Tabela 8

Frequências observadas e estimadas para os anos 2005-09 (vetor inicial no ano de 2005)

\begin{tabular}{|c|c|c|c|c|c|c|c|c|c|}
\hline \multirow[b]{2}{*}{ Estado } & \multirow[b]{2}{*}{$\begin{array}{l}\text { Distribuição } \\
\text { Inicial }\end{array}$} & \multicolumn{6}{|c|}{ Número de transições (anos) } & \multirow{2}{*}{$\begin{array}{c}\text { Estado } \\
\text { estacionário } \\
(\pi)\end{array}$} & \multirow{2}{*}{$\begin{array}{l}\text { Tempo } \\
\text { médio de } \\
\text { recorrência } \\
(1 / \pi)\end{array}$} \\
\hline & & $\begin{array}{c}1 \\
(2013) \\
\end{array}$ & $\begin{array}{c}2 \\
(2017) \\
\end{array}$ & $\begin{array}{c}4 \\
(2025) \\
\end{array}$ & $\begin{array}{c}6 \\
(2033) \\
\end{array}$ & $\begin{array}{c}10 \\
(2049)\end{array}$ & $\begin{array}{c}15 \\
(2069) \\
\end{array}$ & & \\
\hline A & $13,3 \%$ & $17,8 \%$ & $23,7 \%$ & $41,3 \%$ & $62,7 \%$ & $90,89 \%$ & $99,2 \%$ & 1 & 1 \\
\hline B & $8,9 \%$ & $11,9 \%$ & $15,8 \%$ & $21,5 \%$ & $19,0 \%$ & $6,48 \%$ & $0,7 \%$ & 0 & infinito \\
\hline C & $9,6 \%$ & $13,3 \%$ & $15,9 \%$ & $15,3 \%$ & $9,4 \%$ & $1,76 \%$ & $0,1 \%$ & 0 & infinito \\
\hline $\mathrm{D}$ & $9,6 \%$ & $11,1 \%$ & $11,1 \%$ & $7,1 \%$ & $3,5 \%$ & $0,40 \%$ & $0,0 \%$ & 0 & infinito \\
\hline E & $10,0 \%$ & $10,0 \%$ & $8,9 \%$ & $4,6 \%$ & $2,0 \%$ & $0,20 \%$ & $0,0 \%$ & 0 & infinito \\
\hline $\mathrm{F}$ & $10,4 \%$ & $10,0 \%$ & $7,4 \%$ & $3,7 \%$ & $1,4 \%$ & $0,12 \%$ & $0,0 \%$ & 0 & infinito \\
\hline$G$ & $12,2 \%$ & $8,9 \%$ & $6,3 \%$ & $2,8 \%$ & $1,0 \%$ & $0,08 \%$ & $0,0 \%$ & 0 & infinito \\
\hline $\mathrm{H}$ & $11,1 \%$ & $7,8 \%$ & $5,5 \%$ & $2,1 \%$ & $0,6 \%$ & $0,05 \%$ & $0,0 \%$ & 0 & infinito \\
\hline I & $11,5 \%$ & $8,1 \%$ & $4,9 \%$ & $1,5 \%$ & $0,4 \%$ & $0,03 \%$ & $0,0 \%$ & 0 & infinito \\
\hline J & $3,3 \%$ & $1,1 \%$ & $0,4 \%$ & $0,0 \%$ & $0,0 \%$ & $0,00 \%$ & $0,0 \%$ & 0 & infinito \\
\hline \multicolumn{2}{|c|}{$\begin{array}{l}\text { Proporção de pobres } \\
\qquad(\mathrm{H}+\mathrm{I}+\mathrm{J})\end{array}$} & $17,04 \%$ & $10,81 \%$ & $3,62 \%$ & $1,06 \%$ & $0,08 \%$ & $0,00 \%$ & & \\
\hline
\end{tabular}

Fonte: Cálculo dos autores.

Nesse cenário pode-se afirmar que, no período posterior ao Bolsa Família, observouse uma tendência de convergência contrária ao período anterior, ou seja, há convergência positiva. Isso significa que as tendências do período 2005-09 devem ser capazes de alterar a dinâmica do ciclo de pobreza, possibilitando que, com a redução das desigualdades, haja redução da pobreza, atingindo assim o objetivo do Programa. Entretanto, a existência da convergência positiva é um fator necessário, porém não suficiente para afirmar que o Programa Bolsa Família seja eficaz, já que outros fatores além do Programa podem ter contribuído para a redução da pobreza.

Portanto, para comprovar a hipótese de eficácia do Programa, utilizou-se o método diferenças em diferenças (DD), que empregou a variável rendimento mensal domiciliar ${ }^{1}$ para

\footnotetext{
${ }^{1}$ Exceto o rendimento de pessoas cuja condição na unidade domiciliar era de pensionista, empregado doméstico ou parente do empregado doméstico, ou menores de 10 anos de idade.
} 
todas as unidades domiciliares das Pnads de 2004 e $2006^{2}$ definindo dois grupos: um de controle e outro de tratamento. Para formar o grupo de controle foram selecionadas famílias que não receberam o benefício do Bolsa Família e para o grupo de tratamento foram consideradas as famílias beneficiadas pelo Programa. Ao aplicar a equação 6 , considerou-se $S$ igual a 0 quando a família não recebe o benefício e 1 quando recebe; $T$ igual a 1 para todas as famílias amostradas na Pnad em 2006 e igual a 0 para as famílias amostradas em 2004, e ST igual a 1 quando as famílias receberam o benefício do Bolsa Família em 2006. Assim, encontrou-se para DD o valor igual a $-254,29$ com um valor estatístico crítico inferior a $1 \%$; o que indica que as famílias participantes do PBF apresentaram uma renda média superior a $\mathrm{R} \$ 254,49$ em contraste com as famílias não beneficiadas. Portanto, juntamente com os resultados da aplicação do método cadeia de Markov que fornece a condição necessária para a avaliação da eficácia do PBF, o resultado obtido no método Diferenças em Diferenças confirma a hipótese de eficácia desse programa dentro do universo das outras políticas governamentais.

\section{Considerações finais}

Ao propor a utilização dos métodos cadeia de Markov e diferenças em diferenças na análise da eficácia da transferência de renda, este trabalho contribui para o estado da arte do tema, sobretudo pelo fato de não ter sido encontrado na literatura o uso combinado desses métodos em dois períodos distintos para o estudo do impacto de políticas públicas.

Conforme observado nos resultados desta pesquisa, as tendências das políticas públicas de transferências de renda antes da implantação do PBF mostram a ineficácia na ruptura do chamado "ciclo da pobreza". Nota-se que esses resultados corroboram os trabalhos de Soares (2010) e Silva, Yazbek e Giovanni (2008), que afirmam que, neste período, a situação dos programas de transferência de renda condicionada no Brasil era de completo caos gerado pela ausência de acompanhamento, gestão e controle dos programas.

Contudo, no período após a implementação do Bolsa Família, observa-se um melhor índice de mobilidade social e uma tendência de convergência mais rápida para o melhor nível de renda real, no caso, para a classe A, ou seja, uma convergência positiva em apenas 60 anos.

Além disso, todas as classes de pobreza consideradas na análise (H, I e J) são reduzidas para praticamente zero em aproximadamente 40 anos.

Em outras palavras, a probabilidade no ano de 2049 de um brasileiro estar nessas classes é igual a $0,08 \%$. Por fim, de acordo com os resultados, a partir de 2025 vislumbra-se a perspectiva de eliminação da pobreza extrema no país, mantendo-se a tendência no contexto socioeconômico observado no perído 2005-09.

\footnotetext{
${ }^{2}$ No momento da realização da pesquisa não estavam disponíveis os dados relativos ao Programa Bolsa Família na Pnad dos anos de 2007, 2008 e 2009.
} 
Comparando esses resultados com as últimas estatísticas sobre a pobreza no Brasil, observa-se a mesma tendência. Por exemplo, os resultados da presente pesquisa estimam que em 2013 a pobreza, considerando as classes H, I e J, deve representar 17,04\% da população e a extrema pobreza 1,1\%. Entretanto, segundo levantamento do Ipea com base nos dados da Pnad, em 2012, o país constatou uma radical queda nos níveis de pobreza, passando a ter aproximadamente 15 milhões de pessoas vivendo na pobreza (cerca de 8,5\% da população) e perto de 6 milhões na extrema pobreza (quase 3,6\% da população) (Ipea 2013).

A diferença explica-se pelo fato de que aqui apenas se tomou em conta as tendências do período 2005-09, desconsiderando-se os esforços adicionais realizados pelo PBF e o impacto de outros aspetos econômicos dos últimos anos, como: a expansão do PBF, tanto em termos de cobertura, quanto em valor do benefício; o crescimento do salário mínimo real e do valor médio dos benefícios pagos pela previdência social; a redução da taxa média de desocupação de 8,1 em 2009 para 5,5 em 2012, entre outros aspectos socioeconômicos vivenciados no país.

Os resultados da aplicação do método cadeia de Markov foram consubstanciados e complementados com as conclusões do método de avaliação de impacto diferenças em diferenças. Assim, a partir dos resultados desta pesquisa, pode-se afirmar que o Programa Bolsa Família, sem desconsiderar a existência dos demais programas sociais governamentais, além do contexto socioeconômico vigente no período abrangido por esta análise, pode ser capaz de reduzir as desigualdades de renda, alterar e combater a dinâmica do ciclo de pobreza e, consequentemente, fazer com que, no longo prazo, o ciclo de exclusão e a pobreza extrema sejam rompidos.

Percebe-se, no entanto, a necessidade de investigar com maior profundidade a relação entre a redução da pobreza e outras variáveis de influência. A utilização de dados menos agregados também permitiria supostamente uma análise mais apurada da eficácia do Programa. Conforme também enfatizam Pinheiro e Pinheiro (2011), as estratégias governamentais orientadas na perspectiva de políticas públicas com base em crescentes volumes financeiros dispendidos no gasto social federal, embora estejam sendo acompanhadas por melhorias nos indicadores econômico-sociais ao longo do tempo, carecem de maiores evidências que explicitem relações mais estreitas entre a efetividade das políticas sociais do governo e a melhoria do padrão de vida da sociedade em bases sustentáveis.

\section{Referências}

AZZONI, Carlos R. Brasil: una larga historia de disparidades regionales. Qué han hecho (o dejado de hacer) las políticas públicas? Foreign Affairs en Español, v. 9, p. 45-52, 2009.

BAKER, Judy. Evaluación del impacto de los proyectos de desarrollo en la pobreza. Manual para profesionales. Washington, DC: Banco Mundial, 2000.

BANERJEE, Abhijit V.; DULFO, Esther. In equality and growth: what can the data say? Journal of Economic Growth, v. 8, p. 267-99, 2003. 
BARRETO, Flávio A. Crescimento econômico, pobreza e desigualdade: O que sabemos sobre eles? Laboratório de Estudos da Pobreza. Fortaleza: UFC/Caen, 2005. (Série Ensaios sobre a Pobreza).

BARROS, Ricardo P. de; HENRIQUES, Ricardo; MENDONÇA, Rosane. Estabilidade inaceitável: desigualdade e pobreza no Brasil. Rio de Janeiro: Ipea, 2001 (Texto para discussão n. 800).

BARROS, Ricardo P. de et al. A queda recente da desigualdade de renda no Brasil. In: BARROS, Ricardo P. de; FOGUEL, Miguel N. (Org.). Desigualdade de renda no Brasil: uma análise da queda recente. Brasília: Ipea, 2007. v. 1.

BRASIL. Lei n. 10.836, de 9 de janeiro de 2004. Cria o programa bolsa família e dá outras providências. Diário Oficial da União, Brasília, 12 jan. 2004. Seção 1, pt. 1.

BLUNDELL, Richard; DIAS, Mônica C. Evaluation methods for non-experimental data. Fiscal Studies, v. 21, n. 4, p. 427-468, 2000.

BOURGUIGNON, François. The growth elasticity of poverty reduction: explaining heterogeneity across countries and time periods. In: EICHER, Theo S.; TURNOVSKY, Stephen J. Inequality and growth: theory and policy implications. Cambridge: The MIT Press, 2002.

CAETANO, Marcelo A. Previdência social e distribuição regional da renda. Rio de Janeiro: Ipea, 2008. (Texto para discussão n. 1318).

CAMERON, A. Colin; TRIVEDI, Pravin K. Microeconometrics: methods \& applications. Cambridge: Cambridge U. Press, 2005.

CARVALHO JR., Pedro H. B. Análise do gasto da união em ações assistenciais ou focalizado na população pobre e em benefícios previdenciários de fortes impactos sociais: 1995-2004. Brasília: Ipea, 2006. (Texto para discussão n. 1236).

CHAMPERNOWNE, D. G. A model of income distribution. The Economic Journal, v. 63, n. 250, p. 318-351, jun. 1953.

ENDERS, Walter; HOOVER, Gary. The effect of robust growth on poverty: a nonlinear analysis. Applied Economics, v. 35, n. 9, p. 1063-1071, 2003.

FOCHEZATTO, Adelar; STULP, Valter J. A evolução das disparidades regionais no Rio Grande do Sul: uma aplicação de matrizes de Markov. Nova Economia, v. 14, n. 1, p. 39-66, jan./abr. 2004.

GAFAR, John. Growth, inequality and poverty in selected Caribbean and Latin America countries, with emphasis on Guyana. Journal of Latin America Studies. Cambridge University Press, v. 30, n. 3, p. 591-617, 1998.

GERTLER, Paul et al. Impact evaluation in practice. World Bank Publications, 2011.

HOFFMANN, Rasmus. Distribuição de renda: medidas de desigualdade e pobreza. São Paulo: Editora da Universidade de São Paulo, 1998.

HOFFMANN, Rasmus. Transferências de renda e a redução da desigualdade no Brasil e cinco regiões entre 1997 e 2004. Econômica, Rio de Janeiro, v. 8, n. 1, p. 55-81, jun. 2006. 
IPEA. Duas décadas de desigualdade e pobreza no Brasil medidas pela Pnad/IBGE. Comunicados do Ipea, n. 159. Brasília, out. 2013. Disponível em: <www.ipea.gov.br/agencia/images/stories/PDFs/ comunicado/131001_comunicado159.pdf>. Acesso em: 30 jun. 2014.

KAGEYAMA, Angela; HOFFMAN, Rodolfo. Pobreza no Brasil: uma perspectiva multidimensional. Economia e Sociedade, v. 15, n. 1, p. 79-112, 2006.

KAKWANI, Nanak; NERI, Marcelo; SON, Hyun H. Linkages between pro-poor growth, social programmes and labour market: the recent Brazilian experience. Brasil: Pnud, 2006. (Working Paper n. 26).

LADERCHI, Ruhi S.; STEWART, Francis. Does the definition of poverty matter? Comparing four approaches. Poverty in Focus: what is poverty? Concepts and measures. UNDP, International Poverty Centre, 2006.

LAURINI, Márcio; ANDRADE, Eduardo; PEREIRA, Pedro L. V. Income convergence clubs for Brazilian municipalities: a non-parametric analysis. Applied Economics, v. 37, n. 18, p. 2099-2118, 2005.

MARINHO, Emerson; LINHARES, Fabrício; CAMPELO, Guaracyane. Os programas de transferência de renda do governo impactam a pobreza no Brasil? Revista Brasileira de Economia, v. 65, n. 3, p. 267-288, jul./set. 2011.

MEDEIROS, Marcelo; BRITO, Tatiana; SOARES, Fábio. Programas focalizados de transferência de renda no Brasil: contribuições para o debate. Rio de Janeiro: Ipea, 2007 (Texto para discussão n. 1283).

MENEZES, Tatiane A.; SILVEIRA NETO, Raul M.; AZZONI, Carlos R. Demography and evolution of regional inequality. The Annals of Regional Science, v. 49, n. 3, p. 643-655, 2012.

ORSHANSKY, Mollie. Counting the poor: another look at the poverty profile. Social Security Bulletin, v. 28, n. 1, p. 3-29, 1965.

PINHEIRO, Danielle S.; PINHEIRO, Juliana S. Gasto social federal e o papel do Estado na economia no contexto do modelo orçamentário brasileiro. Caderno de Finanças Públicas, n. 11, p. 137-158, dez. 2011.

PÔRTO JÚNIOR, Sabino da S.; RIBEIRO, Eduardo P. Dinâmica espacial da renda per capita e crescimento entre os municípios da região Nordeste do Brasil: uma análise markoviana. Revista Econômica do Nordeste, v. 34, n. 3, p. 405-420, jul./set. 2003.

PRAIS, S. J. Measuring social mobility. Journal of Royal Statistical Society, n. 118, p. 56-66, 1955.

RAVALLION, Martin. Evaluating anti-poverty programs. In: RAVALLION, Martin. Handbook of development economics. Elsevier, 2008. v. 4.

RAVALLION, Martin. Pro-poor growth: a primer. World Bank, 2005. (World Bank Policy Research Working Paper n. 3242).

RECTOR, Robert; LAUDER, Willian F. America's failed \$5.4 trillion war on poverty. Washington, DC: The Heritage Foundation, 1995. 
ROCHA, Francisco J. S.; VERGOLINO, José R. O. Convergência, desigualdade e concentração de renda nas microrregiões do Nordeste brasileiro: 1970-1998. In: ANPEC, 2002, Nova Friburgo. Anais Anpec... 2002.

ROCHA, Sonia. Impacto sobre a pobreza dos novos programas federais de transferência de renda. In: Anais do Encontro Nacional de Economia. Brasília: Anpec, 2004.

ROCHA, Sonia. Pobreza no Brasil. Afinal de que se trata? Rio de Janeiro: FGV, 2006.

SEN, Amartya K. Desenvolvimento como liberdade. São Paulo: Companhia das Letras, 2000.

SEN, Amartya K.; ANAND, Sudhir. Concepts of human development and poverty: a multidimensional perspective. Nova York: UNDP, 1997.

SEN, Amartya K.; DREZE, Jean. Hunger and public action. Oxford: Clarendon, 1989.

SHORROCKS, A. F. The measurement of mobility. Econometrica, v. 46, n. 5, p. 1013-1024, 1978.

SILVA, Maria O.; YAZBEK Maria C.; GIOVANNI, Geraldo. A política social brasileira no século XXI: a prevalência dos programas de transferência de renda. São Paulo: Cortez, 2008.

SOARES, Fábio V. et al. Programas de transferência de renda no Brasil: impactos sobre a desigualdade. In: BARROS, Ricardo P. de; FOGUEL, Miguel N. (Org.). Desigualdade de renda no Brasil: uma análise da queda recente. Brasília: Ipea, 2007. v. 2.

SOARES, Sergei; SÁTYRO, Natália. O Programa Bolsa Família: desenho institucional e possibilidades futuras. In: CASTRO, Jorge A.; MODESTO, Lúcia (Org.). Bolsa Família 2003-2010: avanços e desafios. Brasília: Ipea, 2010.

TAVARES, Priscilla A. Efeito no Programa Bolsa Família sobre o trabalho das mães. In: ENCONTRO NACIONAL DE ESTUDOS POPULACIONAIS. 16., 2008, Caxambu. Anais... Caxambu, 2008.

TOWNSEND, P. Poverty in United Kingdom. Londres: Allen Lane and Penguin Books, 1979.

WORLD BANK. World development indicator 2003. Nova York: Oxford University Press, 2003.

Carlos Rosano Peña é Ph.D em economia pela Universidade Russa Amizade dos Povos, Moscou. Professor do Departamento de Administração da Universidade de Brasília (UnB). E-mail: gmcrosano@gmail.com. Danielle Sandi Pinheiro é doutora em economia pela Universidade de Brasília (UnB). Professora do Departamento de Administração da Universidade de Brasília (UnB). E-mail: danielle.sandi@gmail.com.

Pedro H. M. Albuquerque é doutor em administração pela Universidade de Brasília (UnB). Professor do Departamento de Administração da Universidade de Brasília (UnB). E-mail: pedro.melo.albuquerque@ gmail.com.

Loyane Mota Fernandes é bacharel em administração pela Universidade de Brasília (UnB).E-mail: motaloyane@gmail.com. 
